\title{
Flagrantes no Caleidoscópio
}

\section{Cremilda Medina *}

Resumo: O cenário latino-americano tem oferecido constantes exemplos de estratégias emergentes perante os problemas sociais. A comunicação coletiva também se faz presente no contexto do diálogo Sul-Sul, Sul-Norte. No pensamento, na sensibilidade identitária e na ação política é possível rastrear autores latino-americanos engajados numa narrativa da contemporaneidade criativa e conseqüente com a construção histórica da América Latina.

Palavras-chave: Sociedade e Informação, Autonomia e Identidade Latino-Americana, Diálogo Sul-Sul, Sul-Norte, Estratégias Emergentes e Políticas Sociais.

Abstract: The Latin American scene has offered multiples exemples of emergent strategy facing social problems. The collective communication is also present in the context of the dialogue SouthSouth, South North. It's possible to follow in the thinking, in the sensibility of identity and in the politic action some Latin American authors who are engaged to a contemporary and creative narrative, according to a historic construction of Latin America.

Keywords: Society and Information, Autonomy and Latin-American Identity, South-to-South and South-to-North, Dialogue, Emerging Strategies and Social Polices.

\footnotetext{
* Jornalista, pesquisadora e professora titular da Escola de Comunicações e Artes da Universidade de São Paulo, atua também como docente e orientadora do Programa Latino-Americano de Pós-Graduação da USP. Seu mais recente livro, $A$ arte de tecer o presente, narrativa e cotidiano (Summus Editorial, 2003) se remete à trajetória de prática e teoria na América Latina nas últimas quatro décadas. E-mail: medinase@usp.br. Recebido em 22/05/05 e aceito em 05/06/06.
} 
Aos vinte anos do texto seminal do ensaísta brasileiro Antônio Cândido, impôs-se a visita e a provocação da releitura do autor. Literatura e subdesenvolvimento dos anos 1960 (reeditado em 1987 pela editora Ática no livro Aeducaçãopela noite outros ensaios) trazà tona a fértil interdisciplinaridade entre sociologia e arte, marca do pesquisador emérito da Universidade de São Paulo. "A lei do mundo é a inter-relação e a interação", sentença que revela a perspicácia do pensamento de Cândido, há muito testado na visão humanista do intelectual e na prática militante do cidadão. Ao refletir sobre a América Latina, conjugando arte e ciências sociais, cruzam-se, nesse texto de praticamente 40 anos, o rigor metodológico e a sensibilidade poética e, por isso, literatura e sociedade correm de mãos dadas.

É bom retomar essa trajetória tanto pelo prisma epistemológico quanto pela dimensão ampla das dinâmicas culturais. $\mathrm{O}$ autor publicou primeiramente em francês, numa edição da Unesco, em um tempo que a Europa iria prestar muita atenção nos escritores latino-americanos, ou melhor, hispanoamericanos, a partir das ediçóes de Barcelona e do persistente trabalho da agente literária Carmen Balcels. O despertar para Jorge Luis Borges e para os romancistas que seriam capitaneados pelo boom de Cem anos de solidão, de Gabriel Garcia Marques, estava em gestação quando o ensaio de Antônio Cândido punha em prática sua teoria - consolidada no livro Literatura e sociedade, uma obra que marca a geração 1960, na qual me incluo.

$\mathrm{Na}$ interpretação do texto Literatura e subdesenvolvimento, propóe como hipóteses três grandes etapas da história latino-americana do século XX. Até as primeiras décadas do século passado, predominava entre os ensaístas a consciência amena do atraso. A partir dos anos 1930 se forma a consciência catastrófica do atraso, cuja expressão culminante ocorrerá no pós-Segunda Guerra. Da década de 1960 em diante se acentua uma compreensão que o ensaísta denomina de consciência dilacerada do atraso. Justamente na época em que o texto em questão foi escrito, a América Latina vivia sob a égide da Teoria da Dependência e os intelectuais de esquerda se voltavam para os problemas do subdesenvolvimento. A visão de Cândido se insere, como sociólogo, na corrente a ele contemporânea. Mas, do ponto de vista de interpretação literária, a percepção é original, complexa e duradoura. 


\section{Do dilaceramento à descolonialidade}

Ao aceitar um reencontro com este texto no fim dos anos 1980, o autor ponderou que os impasses da época acentuavam a consciência dilacerada, herança dos escritores tanto da corrente regionalista ou super-regionalista, quanto da corrente urbana. Para ele como para os analistas da cultura, a dramática condição de vida latino-americana está fartamente simbolizada na produção artística. Não há dúvidas quanto à maturidade que se encontra na literatura e demais manifestaçóes da arte. Antônio Cândido reafirmou, naquela visita há quinze anos, uma poética pronta para falar ao mundo, ao Outro e às culturas locais, da condição humana latino-americana. Faltavam, na sua percepção, condições de produção e de circulação. Entrava-se, então, na era da Internet e as promessas de interação digital viriam no bojo da globalização econômica. Seria o dilaceramento da consciência atenuado, a América Latina encontraria na última década do século XX o caminho da maturidade social a exemplo da voz madura de sua expressão literária?

Ao que tudo indica, a resposta é negativa. Causa inquietude o fato de os ensaístas contemporâneos clamarem, outra vez dilacerados pelo horizonte dramático das sociedades do Sul na primeira década do século XXI. Exceto uma ou outra manifestação otimista, a maioria dos autores mobilizam sua consciência cultural para denunciar os descalabros do Norte e de todos os neo da década perdida (neoliberalismo, neo-imperialismo, neocolonialismo, neo-escravismo etc). Curioso considerar a revista Estudos Avançados no 55 (do Instituto de Estudos Avançados da Universidade de São Paulo), que editou, em dezembro de 2005, um dossiê sobre América Latina. O sociólogo Aníbal Quijano, professor da Universidade de San Marcos de Lima, Peru, abre a edição com um cruzamento entre literatura e sociedade. O ensaio Dom Quixote e os moinhos de vento na América Latina lembra Antônio Cândido, não apenas porque as ciências sociais se valem do inconsciente da arte para alertar a consciência da história e da cultura, como pela atualizaçáo das velhas hipóteses do autor brasileiro. Quijano (2005) volta à questão crucial dos historiadores na América Latina, ou seja, o dualismo ocidental EuropaAmérica:

É bom, pois, é necessário que Dom Quixote cavalgue de novo para desfazer agravos, que nos ajude a desfazer o agravo da partida de toda a nossa 
história: a armadilha epistêmica do eurocentrismo que há quinhentos anos deixa na sombra o grande agravo da colonialidade do poder e nos faz ver somente gigantes, enquanto os dominadores podem ter o controle e o uso exclusivos de nossos moinhos de vento.

O ensaio percorre então temas de atualidade como o padrão de poder, a ideologia de raça e a dominação social global e toca, no fundo, nos subterrâneos da cultura. Lá habitam densos fantasmas que dançam na roda do tempo e atravessam as sociedades latino-americanas nos conflitos de identidade, modernidade, democracia e desenvolvimento. Batendo forte na colonialidade do poder como substrato perene, Aníbal Quijano (2005) aflora a consciência dilacerada de Cândido na visão de literatura e sociedade:

Em outros termos, a colonialidade do poder implicava então, e ainda hoje, no fundamental, a invisibilidade sociológica dos não-europeus, 'índios', 'negros' e seus 'mestiços', ou seja, da esmagadora maioria da população da América e sobretudo da América Latina, com relação à produção de subjetividade, de memória histórica, de imaginário, de conhecimento 'racional'. Logo, de identidade.

\section{A digestão dos fantasmas}

Se Quijano recorre a Cervantes para ler o Quixote como metáfora dos fantasmas da América, pode-se ficar por aqui mesmo, na contemporaneidade latino-americana, e perceber, como fez Cândido, que a literatura tem continuamente exorcizado a colonialidade do poder. Tratado da Altura das Estrelas, de Sinval Medina, romance premiado na Primeira Bienal de Literatura de Passo Fundo (1998), mergulhou no duelo do século XVI América-Europa. Publicado a três anos da grande efeméride do Brasil, a trama se passa no início dos 1500 e seus personagens - misto de realidade histórica e mito - simbolizam o encontro-desencontro do nascimento do brasileiro. E não dessas misturas mais ou menos proporcionais, medidas pela herança genética de índio e português ou o mestiço, na interpretação de Quijano. João Carvalho, o piloto português, especialista em rotas de navegaçóes guiadas pela altura das estrelas, trava um conflito com seu filho 
- fruto de um relacionamento com uma índia -, embarcado pelo pai na grande viagem de Fernão de Magalhães.

Carvalho e Carvalhinho, Europa e América, vivem o desencontro nas 312 páginas do romance. Só no fim, por iniciativa que se conscientiza no filho, a colonialidade do poder amadurece na identidade literária. Carvalhinho se libera do fantasma, o Anjo Mau:

- Não existe pecado na terra de onde venho e para onde vou, báfio de Barzebu. Meu pai, que pelos descaminhos da vida e por nefandas artes tuas veio a ser também a certa altura meu inimigo jurado, entra agora em paz na eternidade, já que o devorei com todo o respeito que merece um contrairo morto em leal combate. Doravante, eu sou ele e ele é eu, do que de resto vamos ambos mui contentes e consolados. E com isso, perro satânico, livramo-nos para sempre de tuas diabólicas ciladas. Deixa-te ficar por este Velho Mundo a apequenar consciências como costumas, que no Novo, que é o meu, tem o horizonte outra largueza e a humana existência uma alegria que desconheces.

Antônio Cândido falava da maturidade cultural na literatura e dos entraves de produção e circulação. A consciência dilacerada registrada pela literatura até ao período do ensaio (final dos 60 do século passado) se acentuara vinte anos depois: “(...) a cultura se encontra estrangulada nas condiçóes econômicas, no analfabetismo, na precária difusão do saber, no difícil acesso à universidade, assim como na sua desvitalização”. Quanto de atualidade neste diagnóstico do fim dos anos 1980. Quase duas décadas depois, a voz madura da arte, diante das facilidades tecnológicas, dos avanços democráticos, das conquistas na educação básica e no acesso à universidade, na distribuição planetária, ainda continua estrangulada ou muito lentamente ganha os cenários de decisão histórica para superar a marginalidade. Terá Aníbal Quijano razão ao insistir na colonialidade do poder?

Voltam os fantasmas que, na visão do sociólogo peruano, ainda não foram totalmente exorcizados, embora a literatura, em sua maturidade cultural, represente a antropofagia e a digestáo do mundo europeu no ser americano. Cândido falava, há duas décadas, em estrangulamento e desvitalização. Quijano insiste hoje que a produção da identidade latino-americana "implica, desde o início, uma trajetória de inevitável destruição da colonialidade do poder, uma maneira muito específica de descolonização e de liberação: a descolonialidade do poder.” Mas, para Antônio Cândido, a consolidação 
das literaturas latino-americanas que encantariam os europeus na segunda metade do século XX, revela a consciência dilacerada da condição no Sul, plenamente descolonizada. E dava exemplos significativos: Guimarães Rosa no Brasil, Juan Rulfo no México, Alejo Carpentier em Cuba, entre outros. Identificava, nessa consciência, o reconhecimento do rosto latino-americano, dos fatos da vida social, mas e a ação política para transformá-los? Naquele encontro do fim da década de 1980, o ensaísta questionava se, apesar das promessas de campanha,os políticos mudariam a distribuição de renda, as condições da saúde, da habitação, da educação? Escrevera o texto Literatura e subdesenvolvimento numa época em que apenas conhecia o Uruguai. Depois viajou pelo México, Cuba e Peru. Nas incursóes pelo território, reforçou sua interpretação do imaginário - sim, a literatura espelhava a voz coletiva. Sua esperança se projetava para o século XXI: "Quem sabe se o fio de maturidade cultural latino-americana tecerá a humanização das sociedades."

\section{O gesto precursor da Nova Ordem}

As barreiras, os impasses e as milenares contradições do processo histórico não esmorecem a ação transformadora. Embora a tendência pessimista aflore, arrasadora em certos períodos, o caos é dinâmico como diria Ilya Prigogine. Se o olhar na arte inspira, algumas políticas também desenham caminhos latino-americanos e se anunciam em gestos precursores. As ciências da comunicação, por exemplo, atestam, na América Latina, uma ação ousada que inverteu do fim dos anos 1960 para os 70 o conflito Leste-Oeste para a luta Sul-Norte. Vocalizando a consciência dilacerada da colonialidade do poder informativo exercido pelos países ricos do Norte sobre o Hemisfério Sul, a América Latina foi a regiáo mais progressista, renovadora e pujante do mundo em teoria e política de comunicação social, segundo recente avaliação do Antonio Pasquali, pesquisador venezuelano cuja inserção na Unesco e na Alaic (Asociación Latinoamericana de Investigadores de la Comunicación) marca desse período até hoje a saga da Nova Ordem da Informação.

Em recente entrevista ao periódico da Alaic (Ciências de la comunicación, ańo II, número 2, enero/junio 2005), Antonio Pasquali faz um consistente retrospecto de marcos históricos da ação latino-americana: a criação do Ciespal (Centro Interamericano de Estúdios de Periodismo para América Latina) em 1959, cuja presença teórica e política vai explodir em 1970; em 1974, a 
proclamação da necessidade de uma Nova Ordem Econômica Internacional (Noei) pela Assembléia das Naçóes Unidas; a necessidade de respaldá-la por meio de uma Nova Ordem Internacional da Informação (Tunis, 1976); no mesmo ano, a Conferência para Políticas de Comunicação na América Latina e Caribe em San José da Costa Rica (a primeira de uma série de reunióes regionais); em 1978, a criação na Unesco de uma Comissão Internacional para os Estudos e Problemas da Comunicação que produziria em 1980 o "Informe McBride" (em que participaram Gabriel García Marques e Juan Somavía); em 1978 também se realiza a Conferência Latino-Americana e Caribenha de Políticas Culturais em Bogotá e surge, na Unesco, um Programa Internacional para o Desenvolvimento da Comunicação (PIDC); é de 1980 a Resolução 4.19 que define a Nomic, aprovada por unanimidade na XXI Conferência da Unesco em Belgrado.

Pasquali, na entrevista à pesquisadora venezuelana Migdalia Pineda de Alcázar, cita o histórico das escolas de comunicação social em seu país, bem como a produção bibliográfica latino-americana que mostrará ao mundo a superação também da colonialidade teórica. Ao se transpor a retrospectiva para o Brasil e, em particular, para o pólo da área que implantava o primeiro curso de pós-graduação em Ciências da Comunicação (1972) na Universidade de São Paulo, percebem-se similitudes ao movimento da Venezuela, citado por Pasquali. Cheguei à Escola de Comunicaçóes e Artes (ECA), proveniente da Universidade Federal do Rio Grande do Sul, em Porto Alegre, onde ingressei como docente em 1967, e encontrei um ambiente inquieto. Forças intelectuais agitavam a pesquisa e alimentavam a resistência à ditadura militar brasileira de 1964. Pelas mãos do chefe do Departamento de Jornalismo na época, José Marques de Melo, logo me agreguei ao Ciespal. Em 1972, concretizava meu batismo latino-americano no Equador. $\mathrm{O}$ curso de especializaçáo em Quito, sede do Ciespal, as viagens de pesquisa aos pueblos do país, os estudos na Colômbia e no Peru, na mesma época, enriqueceram a pós-graduação na USP. A partir daí, eu, que só conhecia o Uruguai e a Argentina (quase parafraseando Antônio Cândido), levei um banho de Andes e Caribe. O mergulho na latino-americanidade da Nova Ordem da Informaçáo era inevitável.

Uma estratégia de ação precedeu, na USP, a política formulada no Relatório McBride. Em 1971 se punha em prática a primeira Agência Universitária de Notícias, plenamente sintonizada com a proposta de dar voz à ciência local, 
proclamar a autonomia madura perante o fluxo de colonização informativa. Para além da grande utopia, das agências nacionais do Sul que enfrentariam a dominação do Norte, experimentava-se, na ECA, uma inversão de vetores. A imprensa externa compreendeu muito bem esse rebelde celeiro de informaçóes geradas na universidade. Já os governos militares fizeram fogo cerrado contra a denúncia que chegava até os organismos de repressão: seguidamente a Agência Universitária de Notícias (AUN) era considerada “atentatória à segurança nacional”. Essa é outra história. Um case à parte. Mas o que importa é que não só este laboratório pedagógico formou muitos jornalistas, como sobreviveu às tempestades da ditadura e deu origem a uma mídia profissional, a Agência USP de Notícias, que compóe com as demais mídias a Coordenadoria de Comunicação Social. A originalidade deste complexo uspiano - além da agência de notícias, rede de rádio universitária, televisão, portal, jornal, revista impressa e eletrônica, ações comunicativas e marketing cultural - é, em certa medida, herdeira direta do Direito à Informação na nova geopolítica vocalizada pelo Sul.

Pasquali lembra com propriedade, na entrevista de 2005, a produção teórica latino-americana. As marcas digitais da maturidade cultural que estão presentes na literatura, na arte, se revelam também na ensaística e na bibliografia de comunicação social. Em 1992, ao preparar a conferência de erudição para o concurso de professor titular na Universidade de São Paulo, decidi aproveitar a pesquisa que vinha desenvolvendo - mapear em 50 anos, 1930-1990, os títulos publicados (jornalismo e comunicação) de autores nacionais. A constatação numérica já foi animadora, cerca de 200 obras, salvaguardando as que por certo escaparam ao levantamento. Mas a segunda observação é mais pertinente à avaliação de Antonio Pasquali: a maior parte dos livros foram editados nos anos 1970 a 1980 e seus autores saíram da Escola de Comunicaçóes e Artes da USP. Desnecessário acrescentar que, sem dúvida se trata de uma universidade de pesquisa, em todas as áreas de conhecimento.

Para o autor venezuelano, como para o peruano, não há, porém, espaço para a euforia. Pasquali como Quijano sentem o momento atual desvitalizado, diria Cândido. Os anos 1990 não mostram sintomas de progresso; pelo contrário, a tendência é julgá-los como a década perdida. A própria pesquisa, nesse contexto, não alcançou, nos países latino-americanos, a mínima "dignidade econômica". Para quem, como Pasquali, foi arauto da 
Nova Ordem, o diagnóstico é cáustico, diria até apocalíptico: “(...) nossos Estados ou se desinteressam ou manipulam a comunicação para degradá-la, mas não se assumem como responsáveis da existência de grandes e custosos Serviços Públicos”. Segue comparando a rádio e a televisão na Inglaterra, França, Itália e seus orçamentos de milhóes de dólares com a crise constante da comunicação pública na América Latina. Apesar de tudo, o estudioso vê a força do presente: "Não se deve esquecer nossa situação atípica no âmbito docente, na realidade única no mundo: a região conta com cerca de mil Escolas e Faculdades de Comunicação (só Brasil e México somam umas 600), com mais de 400.000 estudantes." No que pesem os problemas de qualidade, trata-se de uma massa crítica considerável. A pesquisa, por outro lado, cresceu com a formaçáo de mestres e doutores, bem como trabalhos de conclusão de curso na graduação. Se repetisse o mapeamento de títulos publicados nas últimas duas décadas, certamente o volume duplicaria, apesar da carência de recursos para a pesquisa na área.

\section{Davi e Golias no cotidiano}

A consciência cultural e a produção autoral na América Latina flagram, sim, a tragédia social. Mas também vão sedimentando uma produção teórica que põe em diálogo aqui e ali novas políticas públicas da região. Entre os monstros (mais do que fantasmas locais) da contemporaneidade, um deles ganha proporçóes desmesuradas, o desemprego. Análises e mais análises freqüentam os espaços de comunicação social, os papers de congressos científicos ou os encontros informais, familiares. Mas uma pesquisa cuidadosa, focada no abalado Mercosul, pode apontar para políticas públicas animadoras. É o caso de outro texto incorporado ao dossiê da América Latina da revista Estudos Avançados da USP, de autoria da pesquisadora Maria Cristina Cacciamali, da Faculdade de Economia e Administração e presidente do Programa Latino-Americano de Pós-Graduação (USP). A conceituação do Serviço Público de Emprego e Orientação, assim como o desenvolvimento de políticas nos países do Cone Sul estão em curso, embora especialistas como a autora do artigo se posicionem com realismo quanto às limitaçôes.

Ou seja, a consciência dilacerada do desemprego na regiāo (afinal um problema que perturba a consciência universal na contemporaneidade) 
não se entrega à impotência, mas anuncia práticas e desenvolve teorias latino-americanas compatíveis com os fóruns internacionais. $\mathrm{Na}$ revisão de Cacciamali, o Serviço Público de Emprego se consagra na América Latina (sua avaliação se concentra no Cone Sul) a partir dos anos 1990 e dá plena legitimidade ao casamento entre teorias econômicas locais e políticas públicas que atacam a emergência do desemprego, não importam os matizes ideológicos dos governos. O principal eixo de ação é, sem dúvida, a capacitação e treinamento da força de trabalho. A autora identifica o esforço do mercado de trabalho e dos trabalhadores, bem como a necessária intervenção do Estado para acelerar essa qualificação que tende a se concentrar nas empresas com maior fôlego de investimento nesses programas. Convém acrescentar uma terceira força, a da educação, uma vez que universidades e cursos técnicos são cada vez mais mobilizados para pensarem e desenvolverem propostas pragmáticas para acelerar a formação dos profissionais.

O grave problema são os ritmos históricos descompassados e as geraçóes que ficam à margem da sociedade da informação, da terceira etapa da industrialização e da urbanização, da desvalorização das habilidades manuais no campo e na cidade, da cidadania que exige a leitura e a escrita para as decisóes históricas. Não há como fechar os olhos perante esse contingente deserdado e, por mais que os governantes ou políticos de modo geral prometam simétrica aceleração na criação de empregos, o desenvolvimento humano não teve e nem pode ter o mesmo tempo das mutaçóes na tecnologia e no mundo material da economia. Assim como Maria Cristina Cacciamali descreve, em seu artigo, as açóes latino-americanas para a gradual (muito gradual, diria eu) superação dos entraves milenares da exclusão, também na década de 90 do século passado outros ensaístas levantavam a voz. Diga-se de passagem, contra a maré, pois propunham, com ousadia, que era preciso dar comida na boca para os miseráveis, aqueles contingentes sem a mínima condição de se matricularem em programas de capacitação e de ingressarem no mundo do trabalho contemporâneo. Entre essas vozes, a série Novo Pacto da Ciência, que organizo no Fórum Permanente Interdisciplinar da Escola de Comunicaçóes e Artes, ligado também ao Programa Latino-Americano de Pós-Graduação (Prolam) da USP, registra a argumentação de Augusto Franco e Herbert de Souza no volume 3, Saber Plural (1994); e de Sinval Medina, no volume 4 da coleção, Sobre vivências, no mundo do trabalho (1995).

No texto do físico Augusto Franco, há uma firme diferenciação nos 
sentidos de solidariedade e de assistencialismo, o que remete à opçáo éticopolítica da Ação da Cidadania contra a Fome, a Miséria e pela Vida, a hoje consagrada proposta de Betinho. Franco, pragmático, elege, em seu artigo, os militantes de esquerda como interlocutores para contestar a ideologia corrente - a esmola atrasa a revoluçáo. "Se eu não sou capaz de mudar alguma coisa agora, seguramente não serei capaz de mudar o futuro", continua o físico. "Toda a vitória que eu consiga hoje, por menor que seja, está criando condiçóes para a reforma estrutural. Aquela tese de que nós tínhamos de esperar o momento da revolução não se sustenta mais." O escritor Sinval Medina, em seu ensaio Jeito brasileiro de estar no mundo, reflete sobre a condição contemporânea da exclusão, sem esquecer da vivência na América e do paradoxo entre "viver para produzir" ou "produzir para viver". No mundo do trabalho fatores culturais acompanham intimamente as questóes políticoeconômicas. A lógica produtivista que sempre se faz presente não responde bem à circunstância humana e cultural que Medina propunha há doze anos atrás:

(...) está na hora de pensar em meios de vida-vivência (que é um conceito bem mais amplo do que emprego) adequados à realidade que nos espreita na virada do milênio. Ao falar em meio de vida-vivência estou me referindo ao provimento das condiçóes materiais e espirituais de existência através do trabalho, sem dúvida, mas não do trabalho assalariado formal. Começam já a surgir alternativas de canalizar energias para o atendimento das necessidades básicas do ser humano que passam ao largo das soluçôes propostas pela modernidade. Além da consagração da informalidade, da terceirização e de outros modos de aumentar a exploração da mão-deobra, imagino que o futuro reserva, no universo do trabalho, surpresas menos desagradáveis, tais como o surgimento de bolsóes de vida econômica alternativa, onde a lógica do mercado e a maximização de resultados deixem de ser valores absolutos, onde a espiritualidade seja capaz de se contrapor ao apetite de consumo, onde enfim as pessoas passem a trabalhar para viver, e não viver para trabalhar. 


\section{Grandezas e limitações no calor da luta}

No mesmo volume que debatia tendências e utopias para o novo século que se avizinhava, Maria Cristina Cacciamali dava também a sua contribuição ao sistematizar informaçóes sobre a informalidade no mundo do trabalho. Defendia então o que constitui a tônica do texto de 2005 no dossiê sobre a América Latina da revista Estudos Avançados. A atualização de pouco mais de uma década traz as digitais do tempo. No texto escrito em 1994, havia um retrospecto do esforço latino-americano e dos cenários internacionais acionados pelo sinal de alarme do desemprego estrutural. No texto recente, a pesquisadora destaca quatro limitaçóes que, nessa trajetória, representam obstáculos à desejada aceleração dos resultados. A primeira se refere "a defesa irrestrita de que a descentralização dos programas seja mais eficiente e eficaz do que práticas mais centralizadas". Nesse sentido, aponta um problema de comunicação entre as políticas de mercado de trabalho, o que parece inconcebível no mundo da Internet, sem contar as demais mídias concebidas como legítimos vasos comunicantes na sociedade capilar da contemporaneidade. A segunda limitação diz respeito ao universo central da economia - a falta de articulação entre políticas de investimento em geral, políticas de desenvolvimento local e as políticas de trabalho. Para a pesquisadora, a articulação favoreceria a redução da informalidade das atividades econômicas e traria outras vantagens: “(...) aumento do nível local das receitas tributárias e de outros níveis de governos, permitindo maior volume de recursos para políticas públicas, de investimentos e sociais; e maior estabilidade nos contratos favorecendo aumento dos níveis de produtividade e o aprimoramento da qualidade". Na terceira limitaçáo, Cacciamali póe a nu as deficiências dos sistemas de informação dos países da região, velho desafio latino-americano que ascende ao gesto precursor da Nova Ordem da Informação e a esforços conjuntos para haja sinergia e complementação no domínio das políticas públicas e privadas de emprego.

A impaciência da autora com a morosidade da inclusão social, leva à quarta limitação: o ambiente macroeconômico caracterizado pela instabilidade e pelas baixas taxas de crescimento reduz os níveis de desempenho e eficácia de todos os tipos de programa. E aponta o dedo para governantes: "As restrições orçamentárias, perante resultados não significantes, tendem a ser exageradas, muitas vezes por interesses políticos, para reduzirem a agenda 
e/ou a abrangência das políticas ativas de mercado de trabalho, reorientando recursos e propondo açóes assistencialistas de emergência, que provendo renda rapidamente podem render inclusive maiores dividendos políticos, por exemplo, nos programas de transferência de renda adotados em todos os países da região." Tem razáo a articulista quanto à instrumentalização político-eleitoral das açóes pontuais de transferência de renda, mas, por outro lado, a sociedade civil (em seus movimentos organizados e nos grotóes não organizados onde se colhe a voz coletiva através da narrativa dos repórteres que a descobre) cada vez mais assume a consciência dilacerada e clama por comida na boca. Talvez seus netos do excluídos contemporâneos tenham acesso à educaçáo prometida no fim do século XIX e possam freqüentar os programas de capacitação para o mundo contemporâneo do trabalho. Mas quem se contenta com essa lentidão histórica?

\section{Guerrilha homeopática}

A inquietude com os ritmos da História não impede que se sucedam estratégias emergentes em todos os sentidos. A começar pela comunicação social que hoje dá muito mais voz aos gritos dos desajustados, aliás, presentes na arte em todos os tempos. A informação cotidiana e, em particular, a reportagem-ensaio autoral representam, nas narrativas da contemporaneidade. A guerrilha homeopática (para citar Pedro Nava, médico, ensaísta e escritor) que se trava nas sociedades do Hemisfério Sol. Além do registro poético, da ciência comprometida com as demandas sociais, humanas, ambientais, da sociedade civil organizada, dos políticos que escutam a respiração das ruas (proposta de Mário Soares numa campanha eleitoral dos anos 1990 em Portugal) e dos repórteres que desbravam o território do cotidiano dos anônimos, não se pode omitir que alguns fatos acontecem no reino do mercado capitalista.

Um exemplo aleatório: no dia 8 de março de 2006, o jornal $O$ Estado de S. Paulo fez referência a um estudo de Harvard que considerou a política de responsabilidade social da Nestlé como referência internacional. A poderosa multinacional entende que essa ação (denominada creating share value, ou criação de valor compartilhado) não tem a conotação de filantropia. Assumem os autores responsáveis pela política que, de alguma forma, trabalham pela inclusão. Nas conferências dos executivos da Nestlé, cita-se o caso da 
participação na estrutura de negócios da empresa, dos pequenos produtores rurais. Em toda a América Latina, informam, são 300 mil fornecedores de produtos agropecuários, a maior parte de pequeno porte. "Há fornecedores de 10 a 20 litros de leite por dia, que é o que podem produzir. Mas isso movimenta a economia local." Para Paul Burke, um desses executivos da multinacional, a região oferece casos paradigmáticos como o de Caquetá, na Amazônia colombiana. Lá, a Nestlé investiu em programas de aumento da produtividade rural, melhorias na nutrição animal, avanços na genética e desenvolvimento da infra-estrutura das fazendas, organizando um sistema para melhorar a logística do leite produzido em pequenas propriedades. Atualmente a região é responsável por $50 \%$ do leite consumido pela filial colombiana.

O pesquisador Michael Porter, da Harvard Business School, ao estudar este caso, ilumina uma das muitas ações desconhecidas na dinâmica histórica. Por vezes o maniqueísmo que aprisiona as mentalidades não permite compreender contradiçóes no estado de coisas e o pessimismo se traduz em abstração impotente. No dia-a-dia e nas circunstâncias que disparam esse pessimismo há sempre um foco possível que mostra a capacidade de o ser humano se reorganizar no caos e transformar a impotência em atos emancipatórios. Aprendi a lidar com essa noção na vida simbólica, acima de tudo através da arte, e no contato direto com a realidade social como repórter. Fui encontrando também na reflexão ensaística e na ciência dura (já citei Ilya Prigogine) o reforço conceitual da experiência viva na reportagem e da consciência dilacerada na literatura. O território latino-americano oferece oportunidades ímpares de sensibilização, energia indispensável para a ação racional solidária. Neste domínio vêm à tona outras referências bibliográficas das neurociências como o português Antonio Damásio, o colombiano Luis Carlos Restrepo e o brasileiro Henrique Del Nero. Uma oficina de metodologia da construção científica não pode abstrair esta viagem interdisciplinar, assim como o conhecimento acadêmico em muito ganha com a indisciplina da Arte. Cultura e Comunicação Social abrem clareiras para todos os inusitados cruzeiros disciplinares, mas os poetas indicam rotas de antecipação.

Assim aconteceu com a Viagem à África, que sacudiu a poeira do racionalismo estrábico que nos tenta nos escaninhos da Academia. Ao mergulhar nas realidades e nas literaturas dos Cinco da África-Moçambique, Angola, São Tomé e Príncipe, Guiné-Bissau e Cabo Verde, na ordem da viagem 
-, foi preciso enfrentar o velho Adamastor, esse monstro da inviabilidade histórica. Na África, trágico espetáculo da miséria, da guerra, dos desmandos políticos, é possível perceber a tênue dinâmica dos povos sofridos, deserdados universais. Em 1986, quando trabalhava no livro Sonha Mamana África, não acreditava, num primeiro momento, que países assolados por tais mazelas chegassem ao século XXI. No entanto, a criançadinha da rua e os textos de seus poetas me ensinaram a apostar no futuro, a proclamar que, sim, as sociedades africanas enfrentariam os terríveis desafios - o título do livro saiu desse insight. Ou melhor, partilhando com o escritor moçambicano Calane da Silva minha dor e meu pessimismo, perguntei-lhe se a África podia sonhar... Estávamos em um bar austero de Maputo, na noite de 20 de setembro de 1986, e ele pegou um guardanapo de papel e me respondeu:

ainda achas que temos sonhos

ainda achas que estamos vivos

não achas que nós, vivos,

estamos perdidos

pessoano não sou

venho do bairro limitrofe

onde a pólvora do mundo

conosco acabou 


\section{Referências Bibliográficas}

ALCÁZAR, Migdalia Pineda de. Antonio Pasquali: el maestro y su utopía. Entrevista publicada na Revista Ciencias de la Comuicación, ALAIC, año II, n. 2, enero-junio. 2005.

CACCIAMALI, Maria Cristina. As políticas ativas de mercado de trabalho no Mercosul. Revista Estudos Avançados, São Paulo, Universidade de São Paulo, v. 19 n. 55, setembro-dezembro. 2005.

CANDIDO, Antônio. Literatura e subdesenvolvimento. In: A educação pela noite e outros ensaios. São Paulo: Ed. Ática, 1987.

DAMASIO, António. O erro de Descartes, emoção, razão e cérebro humano. São Paulo: Cia. das Letras, 2003.

DEL NERO, Henrique. O sitio da mente, pensamento, emoção e vontade no cérebro humano. São Paulo: Collegium Cognitio, 1997.

FRANCO, Augusto. Solidariedade: opção ético-política. In: MEDINA, Cremilda; GRECO, Milton (Org.). Saber plural, novo pacto da ciência 3. São Paulo: ECA/USP, 1994.

MEDINA, Cremilda. Interacción, la ley del mundo (o la voz madura de América Latina). Revista Diálogos de la Comunicación, Lima, FELAFACS, n. 4, 1990. . Sonha Mamana África. São Paulo: Edições Epopéia, 1987. - A posse da terra, escritor brasileiro hoje. Lisboa: Imprensa Nacional-Casa da Moeda, 1985 (vide texto sobre Pedro Nava em que o autor utiliza a metáfora da guerrilha homeopática).

MEDINA, Sinval. Tratado da altura das estrelas. Porto Alegre: Instituto Estadual do Livro, Editora da PUC/RS, 1997.

. Jeito brasileiro de estar no mundo. In: MEDINA, Cremilda; GRECO, Milton (Org.). Sobre vivências, novo pacto da ciência. São Paulo: ECA/USP, 1995.

PRIGOGINE, Ilya; STENGERS, Isabelle. A nova aliança. Brasília: Ed. da UnB, 1984. 
QUIJANO, Aníbal. Dom Quixote e os moinhos de vento na América Latina. Revista Estudos Avançados, São Paulo, Universidade de São Paulo, v. 19, n. 55, setembro-dezembro. 2005.

RESTREPO, Luis Carlos. Direito à ternura. Petrópolis: Vozes, 1998.

SOUZA, Herbert de. A alma da fome é política. In: MEDINA, Cremilda; GRECO, Milton (Org.). Saber plural, novo pacto da ciência 3. São Paulo: ECA/USP, 1994. 